\title{
Valvar prosthetic dysfunction Localisation and evaluation of the dysfunction using the Doppler technique
}

\author{
COLETTE VEYRAT, S WITCHITZ, A LESSANA, A AMEUR, G ABITBOL, \\ D KALMANSON \\ From the Service de Cardiologie, Fondation A de Rothschild, Paris, France
}

SUMMARY Thirty patients with 33 mitral or aortic prostheses or both were examined using the pulsed Doppler technique combined with cross sectional echocardiography to study the applicability of the Doppler technique in the diagnosis and evaluation of the severity of prosthetic dysfunction and to assess the ability of the mapping procedure to estimate the site and the size of the prosthetic defect. The dysfunction was valvar regurgitation in 29 instances and stenoses in eight, all of which were confirmed by invasive procedures. The severity of the dysfunction was graded on a three point scale. A control group of 73 subjects with 88 normal prostheses also underwent pulsed Doppler and cross sectional echocardiography. The pulsed Doppler study followed the usual procedure for a valvar disease including two and three dimensional mapping for regurgitation. Eight patients also underwent a continuous wave Doppler examination.

The diagnostic reliability of the pulsed Doppler technique was $\geqslant 90 \%$. The severity of the dysfunction was accurately assessed in $86 \%$ of cases. In the case of aortic regurgitation, mapping of the jets was performed as easily for prostheses as for native regurgitant valves. In the case of mitral regurgitation, the mapping patterns depended on the cause of the dysfunction. With valvar tears, a jet was detected at the centre of the annulus, and with paravalvar leaks eccentric atrial jets were seen opposite the site of the leak.

The pulsed Doppler and the surgical findings correlated well for both the site of the dysfunction $(16 / 20(80 \%)$ patients) and the size of the leak (13/16 (81\%) patients).

Thus, despite some limitations, pulsed Doppler and particularly the mapping procedure provide sufficient information to give an accurate non-invasive assessment of prosthetic valve dysfunction.

The detection of prosthetic dysfunction is incomplete with the usual non-invasive techniques. ${ }^{1}$ The limitations of echocardiography in examining bioprostheses are fewer than with mechanical prostheses, ${ }^{23}$ and echocardiography may be helpful in detecting left atrial thrombi ${ }^{4}$ or abnormal kinetics. ${ }^{5}$ Nevertheless, the results of echocardiography may be ambiguous in a number of cases. Phonocardiography is sensitive ${ }^{6}$ but does not provide any information on the extent of the dysfunction or its site. With the Doppler technique, Holen and Nitter

Requests for reprints to Dr Colette Veyrat, Chargé de Recherches au Centre National de la Recherche Scientifique, Service de Cardiologie, Fondation A de Rothschild, 25-29 rue Manin, 75940 Paris Cedex 19, France.

Accepted for publication 12 April 1985
Hauge have shown that the transprosthetic atrioventricular gradient may be measured using the continuous wave Doppler technique, ${ }^{7}$ and a few isolated cases of dysfunction have been reported using the pulsed or continuous wave Doppler technique. ${ }^{89}$ In addition, the pulsed Doppler technique makes it possible to grade the severity of the acquired valvar defect on the basis of velocity patterns ${ }^{81011}$ or indices of severity. ${ }^{12-14}$ Moreover, the mapping procedure helps in identifying the site of the dysfunction. We applied this technique to determining the severity of the prosthetic dysfunction and to identifying its site.

\section{Patients and methods}

The study population consisted of 30 patients (14 
Table 1 Types of prostheses investigated with the Doppler technique

\begin{tabular}{lcc}
\hline Type of prosthesis & $\begin{array}{l}\text { Malfunctioning } \\
\text { prostheses }\end{array}$ & Normal prostheses \\
\hline Aortic: & 7 & 19 \\
Starr-Edwards & 3 & 4 \\
Björk & 3 & 11 \\
Bioprostheses & 1 & 1 \\
St Jude & 3 \\
Miscellaneous & 14 & 38 \\
Total & & 31 \\
Mitral: & 6 & 5 \\
Starr-Edwards & 3 & 6 \\
Björk & 9 & 2 \\
Bioprostheses & 1 & 2 \\
Gabbay Meadox & 19 & 46 \\
Miscellaneous & & 3 \\
Total & & \\
Tricuspid: & & 1 \\
$\quad$ Starr-Edwards & & 88 \\
Pulmonary: & & \\
Bioprosthesis & 33 & \\
Total & & \\
\hline
\end{tabular}

women and 16 men, mean age 48 years) with 33 malfunctioning prostheses (Table 1), in whom the prosthetic dysfunction was diagnosed by invasive procedures including left heart catheterisation with left ventricular cineangiograms or aortic root angiograms or both (21 cases), or surgery (21 cases), or at necropsy (one case). The dysfunction was valvar regurgitation or obstruction, or both (37 instances, involving 38 causes since regurgitation was due to both a paravalvar leak and a valvar tear in one patient). Table 2 shows the cause of the dysfunction identified at surgery or necropsy. Twenty patients were in sinus rhythm and six in atrial fibrillation; three had implanted pacemakers and one incomplete atrioventricular block.

A control group of 73 patients ( 38 women and 35 men, mean age 54 years) were examined at the same time. They had 88 normally functioning prostheses (Table 1) on the basis of no cardiac symptoms

Table 2 Type of prosthetic defects causing regurgitation or obstruction. Figures are number of defects

\begin{tabular}{llc}
\hline & $\begin{array}{l}\text { Mitral } \\
\text { valve }\end{array}$ & $\begin{array}{c}\text { Aortic } \\
\text { valve }\end{array}$ \\
\hline \multicolumn{1}{c}{ Regurgitation } & & \\
$\begin{array}{l}\text { Paravalvular leak: } \\
\quad \text { Primary }\end{array}$ & 5 & 2 \\
$\begin{array}{l}\text { Secondary to endocarditis } \\
\text { Valvar lesion on bioprosthesis: }\end{array}$ & 4 & 5 \\
$\quad \begin{array}{l}\text { Primary } \\
\text { Secondary to endocarditis }\end{array}$ & 2 & \\
$\begin{array}{l}\text { Unknown origin } \\
\text { Endocarditis vegetations }\end{array}$ & 2 & 1 \\
Thrombus & 5 & 4 \\
$\begin{array}{l}\text { Fibrosis or calcifications } \\
\text { Unknown origin }\end{array}$ & 1 & 2 \\
Total & 1 & 1 \\
\hline
\end{tabular}

^Patients who did not undergo repeat surgery. detected at clinical examination or by phonocardiography and echocardiography. In 10 controls with transient equivocal clinical data a later invasive study failed to detect a prosthetic dysfunction.

\section{CLASSIFICATION OF THE DYSFUNCTION}

For patients who had undergone angiography the severity of the dysfunction was graded as mild, moderate, or severe. ${ }^{11-13}$ For patients who had undergone repeat surgery the classification was based on the presence of vegetations, thrombosis or fibrosis or both, calcification (in the case of obstruction), valvar perforation (in the case of bioprostheses), and the extent of the annular leak in relation to the whole circumference of the prosthesis (mild, disruption of a few points; moderate, disruption equal to a quarter of the circumference; severe, disruption equal to a third of the circumference). The same classification was used for the findings at necropsy.

\section{DOPPLER ECHOCARDIOGRAPHY}

We used a $3 \mathrm{MHz}$ ATL 851 (Squibb Medical System, Bellevue, Washington, USA) mechanical real time scanner, which provided a $90^{\circ}$ sector and single gate steerable pulsed Doppler capability. The Doppler output could be presented as an audible signal, a time interval histogram, an analogue flow velocity trace, and a real time frequency spectrum by means of a fast Fourier transform analyser (Angioscan) (Unigon Industries, Mount Vernon, New York, USA). The principles and characteristics of the instruments have been described elsewhere. ${ }^{15-17}$

For eight patients and 22 controls we also used a $2.5 \mathrm{MHz}$ continuous wave Doppler SONACOLOR CD (Carolina Medical Electronics, King, NC, USA). This instrument shows the positive or negative Doppler shifts from the zero reference to 20 $\mathrm{KHz}$ since the polarity may be switched. Real time spectral analysis is performed every $10 \mathrm{~ms}$ over a selectable frequency range to provide the equivalent of 256 band pass filters spaced at $100 \mathrm{~Hz}$ intervals. ${ }^{18}$ A thermal colour coded scale from red (weak signal) to white (strong signal) indicates the amplitudes within the spectrum. Audiosignals are also simultaneously fed to stereo speakers. The pulsed Doppler signal may also be fed to the instrument for real time spectral analysis. ${ }^{19}$ One recording was made using a $2 \mathrm{MHz}$ continuous wave instrument (Alfred) (Pedof, Vingmed A/S, Norway).

The procedures used for investigating prostheses with pulsed Doppler are similar to those already described for left sided valvar defects. ${ }^{20}$ For aortic prostheses, we recorded the aortic velocity traces from the suprasternal notch and in the left parasternal long and short axis views (at aortic and left 


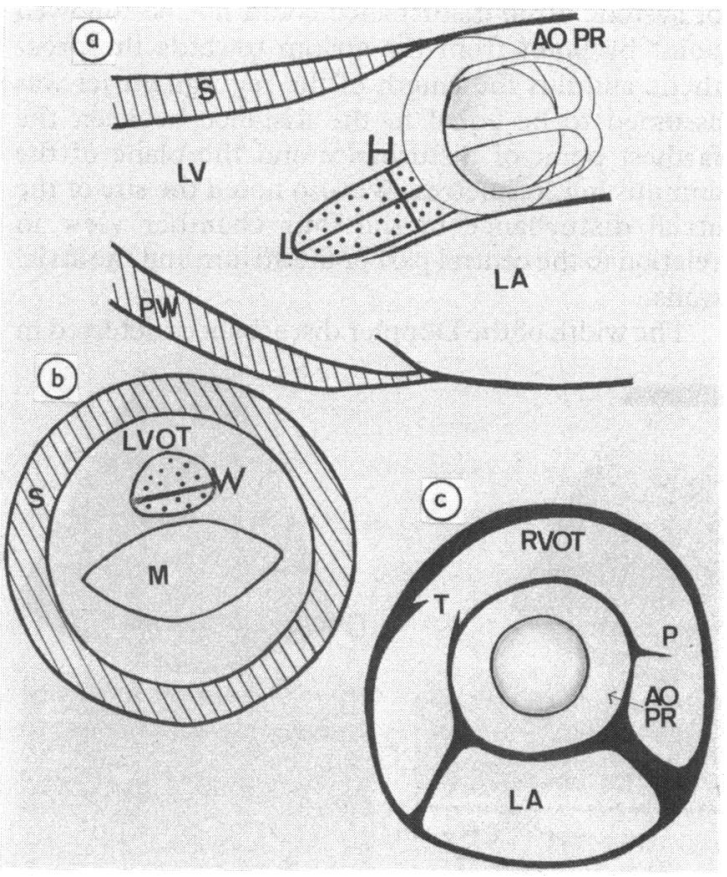

Fig. 1 Diagrams showing the calculation of the left ventricle outflow tract regurgitant index for assessing the severity of aortic regurgitation in a prosthetic aortic valve: the product of the length $(L)$ and height $(H)$ of the disturbed area in relation to the regurgitant flow (dotted areas) in the parasternal long axis view (a) and of its width $(W)$ in the parasternal transverse aorta short axis view (b) equals the left ventricle outflow tract regurgitant index. (c) Shows the entire aortic prosthesis in the transverse aorta short axis view for the diagnosis and evaluation of both stenosis and regurgitation (regurgitant aortic valvar area). S, septum; $R$ or LVOT, right or left ventricle outflow tract; $L A$, left atrium; $M$, mitral valve; $T$, tricuspid valve; $P$, pulmonary valve; $P W$, posterior wall; $A O P R$, aortic prosthesis; $L, H, W$, length, height, and width of the disturbed area in centimetres.

ventricular levels) (Fig. 1). For mitral prostheses (Fig. 2), we recorded the traces in (a) the long axis parasternal view using, if necessary, the manoeuvre recommended by Nishimura $e a^{21}$ in order to transsect the prosthetic annulus in more than one longitudinal plane, $(b)$ the short axis plane, paying particular attention to the intermediary plane between the level of the aortic and mitral orifices, in order to scan the anterior part of the prosthetic ring, and $(c)$ the four chamber view and, more rarely, the subcostal approach.

When the continuous wave mode is used the angle $\theta$ between flow and the ultrasonic beam should be reduced as much as possible so we generally sited the probe in the suprasternal notch for aortic prostheses and at the apex of the heart for mitral prostheses. ${ }^{22} 23$
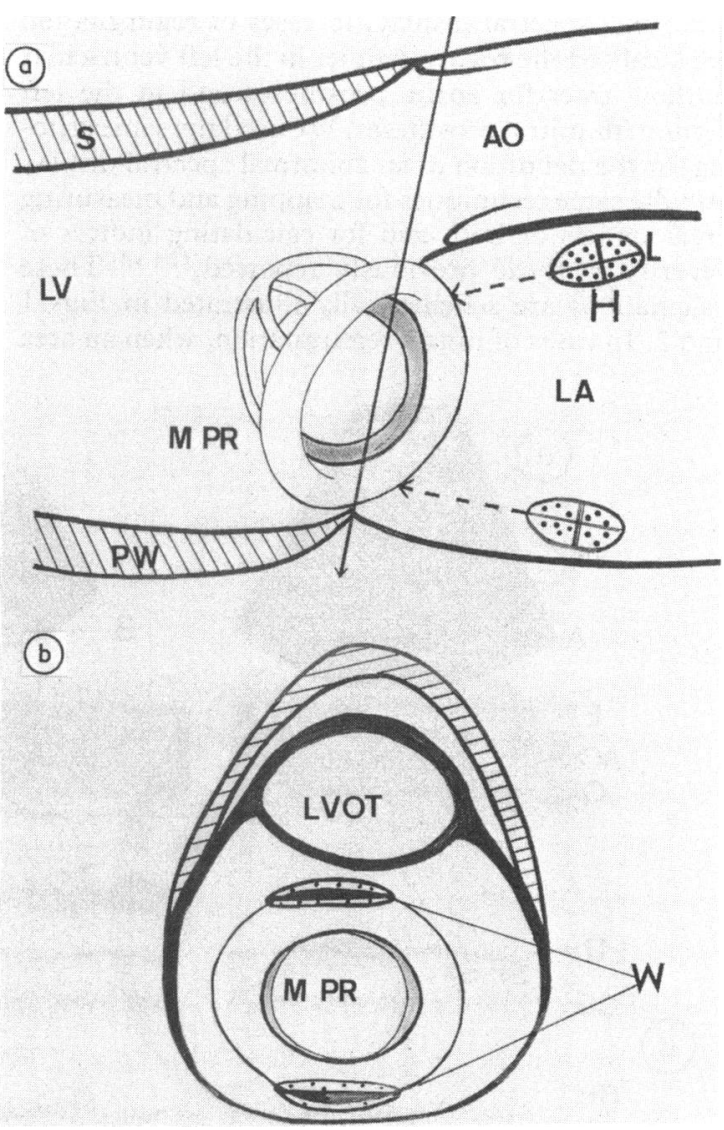

Fig. 2 Diagrams showing the calculation of the total regurgitant index in assessing the severity of mitral regurgitation in a mitral prosthesis. In (a) the length and height of the disturbed area in relation to the regurgitant flow (dotted area) are measured and the long axis regurgitant index calculated as $1 / 2 \mathrm{~L} \times \mathrm{H}$. When the disturbed area is not followed from the centre of the prosthesis the length is considered to be equal to the distance of the farthest atrial disturbance from the plane of the annular prosthesis (dotted line). In (a) the prosthesis is drawn in perspective, whereas in (b) the heart is transsected along a single plane. The oblique line in (a) transsecting the left cavities corresponds to the level of the short axis plane used in (b) for the measurement of the width (W) of the regurgitant flow, which is the short axis regurgitant index. The total regurgitant index is equal to $(1 / 2 L \times H) \times W$. The apical four chamber view usually used to record the mitral flow velocity traces is not shown. ( $A O$, aorta; $M P R$, mitral prosthesis; for other abbreviations see Fig. 1).

\section{VARIABLES STUDIED}

Pulsed Doppler-The aortic and mitral velocity traces were examined for both the presence or the absence of systolic or diastolic disturbances in all patients. $^{81011}$ In addition, we localised areas of 
abnormal spectral display; in cases of regurgitation we localised the regurgitant jet in the left ventricular outflow tract for aortic prostheses and in the left atrium for mitral prostheses. We used the same criteria for the definition of an abnormal spectral display and the same techniques for mapping and measuring areas or jets or both and for calculating indices of severity as those previously reported. ${ }^{12-14}$ These calculations are schematically illustrated in Figs. 1 and 2 . In cases of mitral regurgitation, when an area of systolic atrial disturbance could not be followed point by point from the atrium towards the prosthetic annulus the length of the regurgitant jet was assumed to be equal to the distance between the farthest point of disturbance and the plane of the annulus in centimetres. We also noted the site of the atrial disturbance in the four chamber view in relation to the central part of the atrium and the atrial walls.

The width of the Doppler disturbances detected in

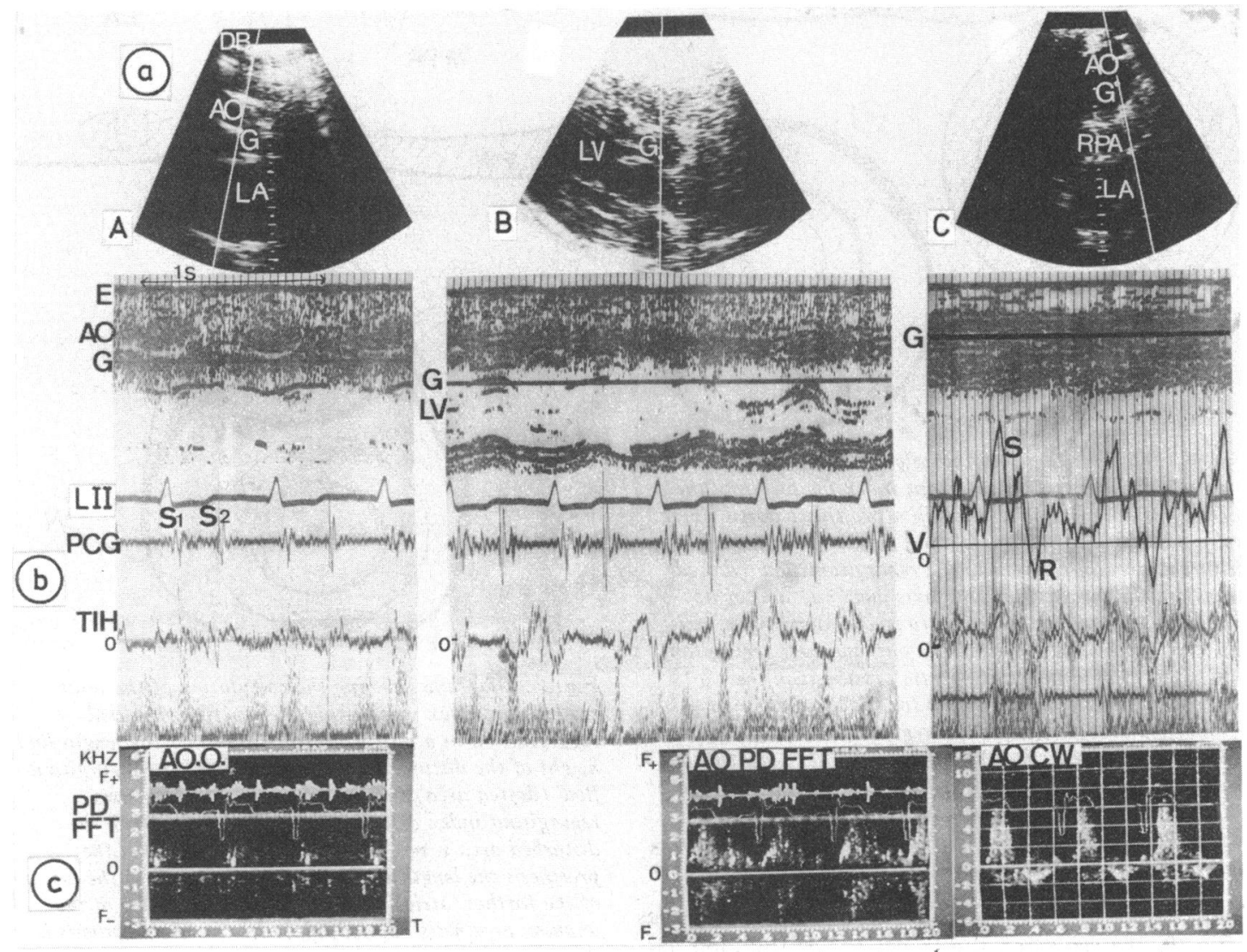

Fig. 3 (a) Cross sectional echocardiograms, (b) pulsed Doppler recordings with the signal fed to a zero crossing meter and (c) to a fast Fourier transform real time analyser (of a normal aortic prosthesis). ( $A$ ) shows the transverse aorta short axis view (the Doppler beam is shown as a white line $(D B)$ and the gate as a white spot $(G)$ at the level of the prosthesis). (B) the parasternal long axis view (the gate is in the left ventricle outflow tract beneath the aortic valve; the spectrum consists of a line of clustered dots in both parts of the cardiac cycle), and (C) the suprasternal approach of the ascending aorta (the gate is in the aorta). (b) (left and middle panels) shows two systolic deflections related to the opening and closing of the cusp and some transient early systolic minor broadening of the spectrum, which is shown as a thin line for the remainder of the cardiac cycle. The same pattern is for the real time spectrum analysis. (b) (right panel) shows one systolic positive $(S)$ and one transient negative in early diastole $(R)$ with no more negativity in the remaining part of diastole. In this case, velocities reached $1.80 \mathrm{~m} / \mathrm{s}$ as shown by the recording using continuous wave Doppler (c, right panel). Some segments of the venous pattern are superimposed on the arterial pattern with this equipment. DB, Doppler beam; $G$, gate; RPA, right pulmonary artery; LII, lead II of the electrocardiogram; PCG, phonocardiogram; $S_{1}, S_{2}$, first and second heart sounds; TIH, time interval histogram; $V$, velocity trace; $O$, zero line; $A O O$, aortic orifice; $P D F F T$, pulsed Doppler signal fed to a fast Fourier transform analyser, $C W$, continuous wave Doppler; KHz, kilohertz; F+, F-, positive and negative Doppler shift; $T$, time axis (other abbreviations as in previous Figs). 
the short axis view, representing the size of the leak, was expressed as a percentage of the circumference and compared with the surgical findings.

Continuous wave Doppler-The blood velocities were calculated on the basis of $0.30 \mathrm{~m} / \mathrm{s}$ for $1 \mathrm{KHz}$ Doppler shift, assuming optimal alignment between the flow and the ultrasonic beam. The half pressure time and the pressure gradient were calculated when appropriate from the simplified Bernouilli equation: $\mathrm{P}_{1}-\mathrm{P}_{2}=4 \mathrm{~V}_{2}$, according to Hatle et al and Holen et al. . $^{23-25}$

Recordings were made either on a Sony videotape recorder with hard copies of real time imaging on a 4633 Tektronics recorder, or on a Panasonics videotape, with imaging using polaroid film. Simultaneous electrocardiograms (lead II), phonocardiograms, and $M$ mode echocardiograms were usually recorded with the pulsed Doppler display on an IREX 101 (IREX, Mahwah, NJ, USA) multitrace system. All recordings were performed by two independent observers and each of them reviewed the videotapes. There was no significant interobserver and intraobserver discrepancy between the results $(r=0.95$ and 0.97$)$. The conclusions drawn from the Doppler data were made independently from the results of the invasive procedures and were performed by separate teams.

\section{Results}

NORMAL PROSTHESES (Figs. 3 and 4)

The Doppler technique did not show any abnormality in 85 of 88 prostheses. In the remainder minor aortic (2) and mitral (1) regurgitation without any measurable jet was not confirmed by other clinical

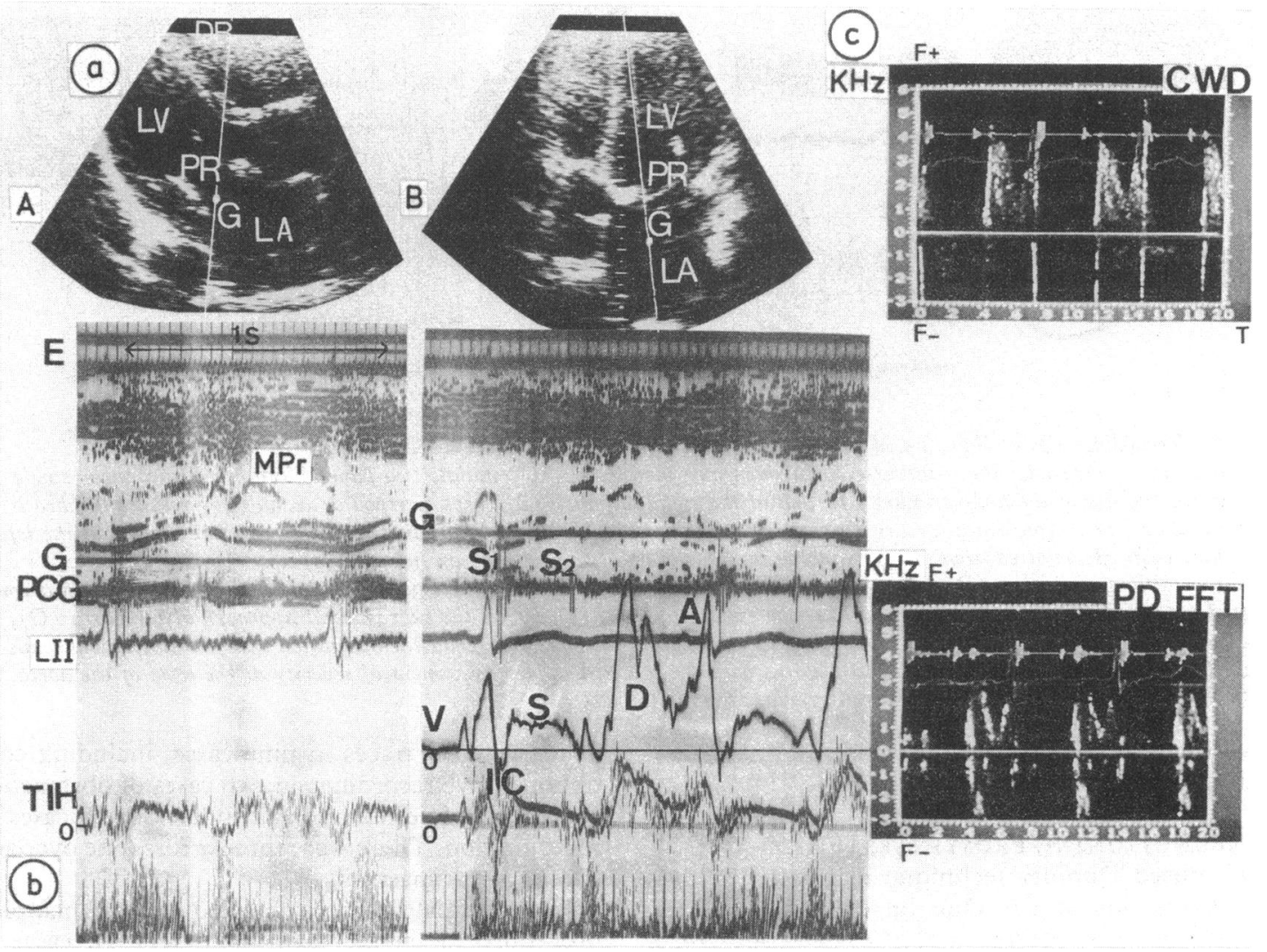

Fig. 4 (a) Cross sectional echocardiograms, (b) pulsed Doppler recordings, and (c) real time analyses of a normal mitral prosthesis. (A) shows the parasternal long axis view with the gate at the annulus (the Doppler spectrum consists of a thin line of clustered dots; the same features would be recorded at the annulus in the short axis view), (B) the apical four chamber view (the mitral flow velocity trace is recorded with its four constitutents) IC due to the isometric contraction and $S$ at or slightly above the zero line in systole and the two filling diastolic waves $D$ and $A$ (some frequency aliasing may be seen in early diastole, which is better shown in (c) bottom panel; (c) (top panel) shows the continuous wave Doppler trace. (Abbreviations as in previous figures.) 

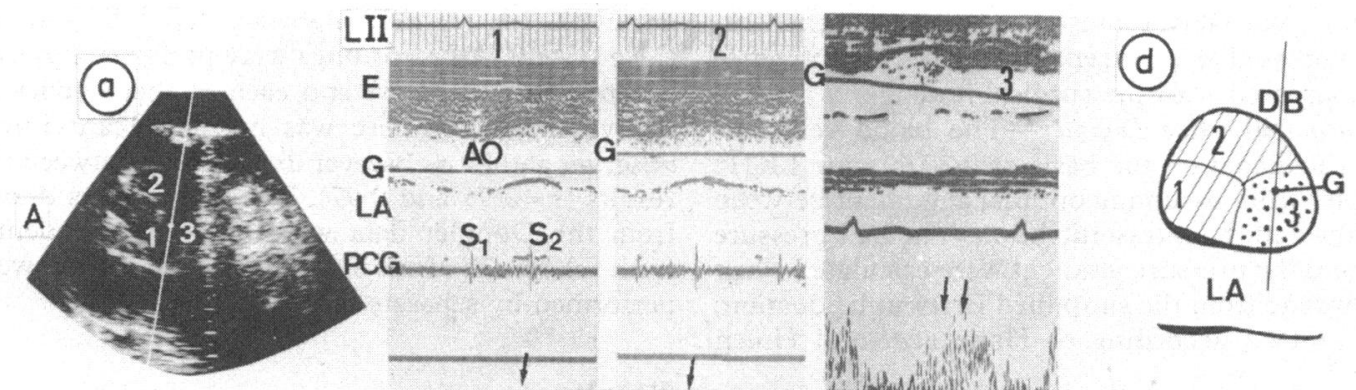

Fig. 5 Recordings (as in Figs. 3 and 4) showing severe dysfunction of a Hancock bioprosthesis with stenosis and regurgitation. (a) Shows the transverse aorta short axis view $(A),(a)$ (middle two panels) systolic disturbance (single arrow) at the site of the non-coronary (1) and of the right coronary (2) cusps (striped areas on (d)) related to fibrosis and calcifications as confirmed at surgery and (a) (right panel) diastolic disturbance (twin arrows) at the site of the left coronary cusp (3) (dotted area on (d)) owing to destruction of this cusp by an infective process. (b) Shows the parasternal long axis view (B) (the gate is in the left ventricle) and (b) (right panel) diastolic disturbances (twin arrows, dotted area); the regurgitant index is 20 (severe regurgitation). (c) Shows the suprasternal approach of the aorta (C), and (c) (right panel) both stenosis and regurgitation. The systolic pressure gradient calculated with the continuous wave was $40 \mathrm{~mm} \mathrm{Hg}$ (moderate stenosis), which agrees with the pulsed Doppler assessment of severity at the level of the aorta. ( $P R$, prosthesis, other abbreviations as in previous figures.)

investigations; one patient later had a normal angiogram.

DYSFUNCTIONING PROSTHESES (Figs. 5-7)

The pulsed Doppler technique diagnosed 35 dysfunctions out of 37 . One false negative aortic obstruction was detected at necropsy and one case of mitral regurgitation was due to a valvar tear. Three paravalvar leaks were not identified in cases of regurgitation (one mitral leak associated with a valvar tear and two aortic leaks). The sensitivity, specificity, predictive value, and accuracy were $94 \%, 96 \%$, $92 \%$, and $96 \%$ respectively. The evaluation of the severity of the dysfunction relied on the examination of the velocity traces in nine cases, including con- $\rightarrow$ tinuous wave recordings in two cases of obstruction and on the determination of indices in 26 cases of $N$ regurgitation. There were three errors (one over and two underestimations).

No abnormalities were detected with the mapping procedure for aortic regurgitant jets. In cases of mitral regurgitation, the long axis view showed systolic disturbances at the centre of the annulus $\mathbb{D}$ entailing a central atrial jet in the same plane and in :the four chamber view in only five patients. Among the remaining patients, these disturbances were $\overrightarrow{\mathbb{D}}$ found only in the left atrium away from the annular $\frac{?}{\mathrm{D}}$ centre. In these patients the annular detection was 


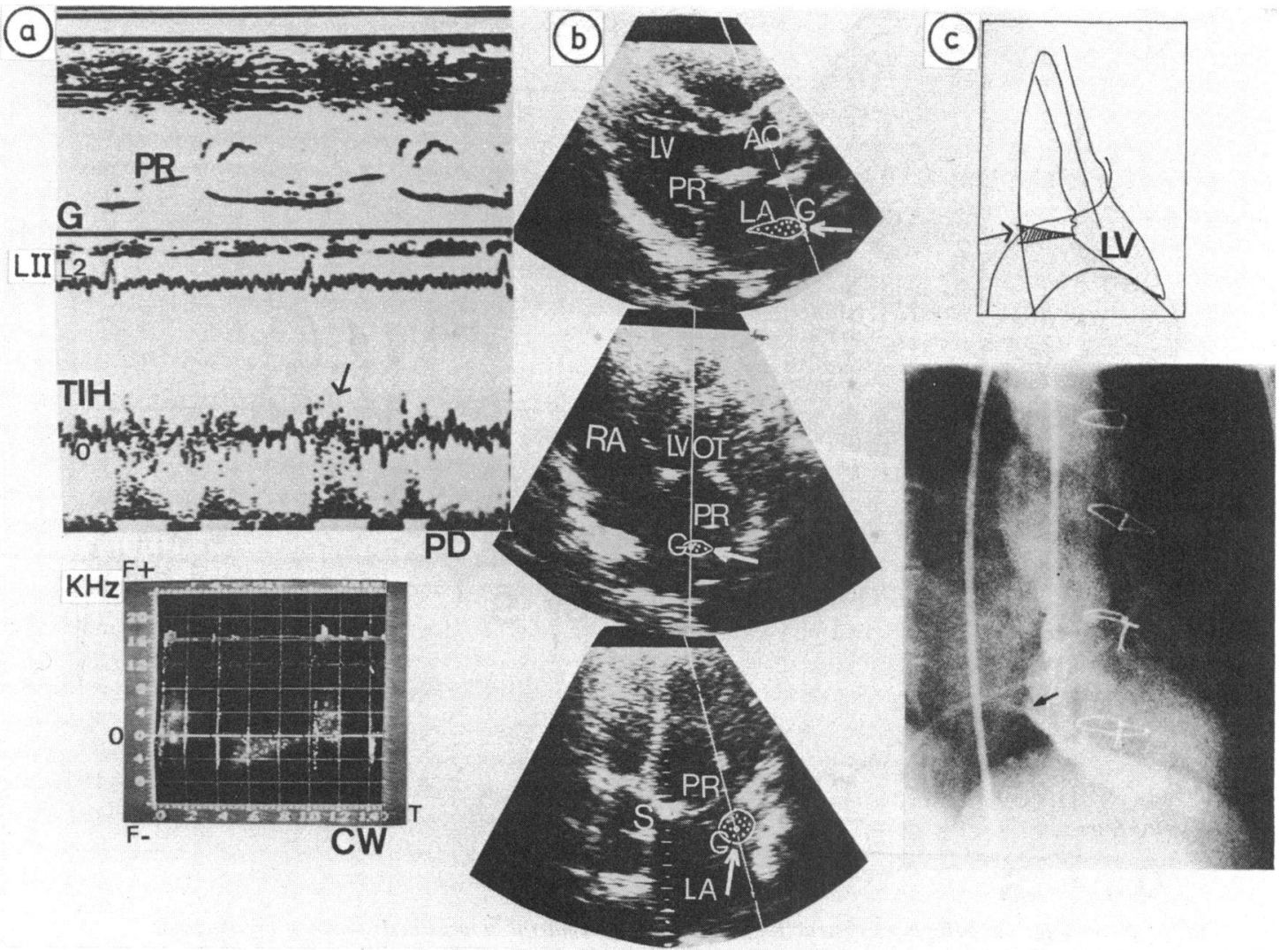

Fig. 6 (a) Pulsed Doppler recordings (top and middle panels) and continuous wave recording (bottom panel), (b) cross sectional echocardiograms, and (c) angiogram showing a paravalvar leak on a mitral Gabbay Meadox prosthesis. (a) Shows early systolic disturbance in the left atrium (arrow). The velocity of the regurgitant jet is $3 \mathrm{~m} / \mathrm{s}$ as shown by the continuous wave Doppler (the Doppler shift has been artificially reversed and velocities related to the regurgitation are positive, although the probe is at the apex). (b) Shows these spectral disturbances at three sites: top, in the left atrium seen in the long axis view along the posterior wall; middle, at the centre of the posterior part of the annulus in the short axis view; bottom, below the previous attachment of the posterior leaflet in the four chamber view (dotted areas shown by white arrows). The total regurgitant index is 2.5 (mild regurgitation). (c) Shows a discrete regurgitant jet at the inferior part of the annulus. At the time of the operation, there was a $8 \mathrm{~mm}$ paravalvar leak at the centre of the previous area of insertion of the posterior leaflet. The patient underwent surgery because of severe haemolysis. (Abbreviations as for previous figures.)

assessed only in the short axis view. When the three approaches are combined the following Doppler features were noted for this group: five patients had posterior annular systolic disturbances in the short axis view, with some additional ones in the lower half of the atrium in the long axis view and near the external atrial wall in the four chamber view; six patients had anterior annular systolic disturbances in the short axis view, with some additional ones in the upper half of the atrium in the long axis view and towards the interatrial septum in the four chamber view.

Table 3 shows the size of the annular ring and the width of the Doppler abnormalities in 13 patients with paravalvar leaks.
The site of the dysfunction was confirmed at reoperation in $16(80 \%)$ of 20 patients (Table 4$)$. Paravalvar leaks were present along the previous attachment of the anterior mitral valve (three patients) and of the posterior valve (three patients), and they overrode the previous posterior (one patient) and anterior (one patient) commissures. In these two instances, Doppler detected only a posterior and an anterior site. For the aortic orifice, it was not possible to determine accurately the site of the disturbance in one patient with poor echocardiographic visualisation of the aortic annulus, although measurements could be performed. The Doppler technique detected two paravalvar leaks along the non-coronary cusp, one along the right 


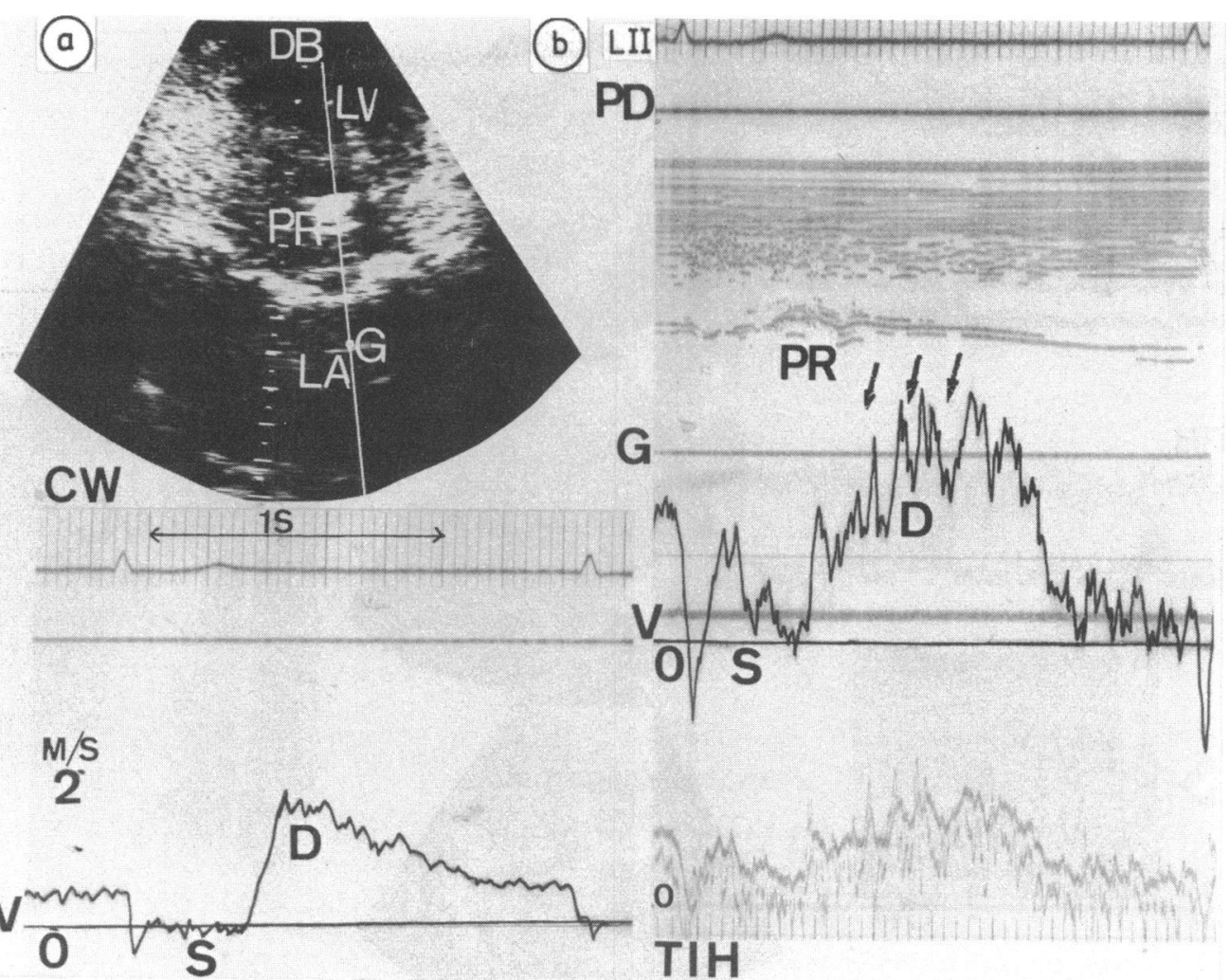

Fig. 7 Recordings (as before) of obstructive dysfunction of a mitral bioprosthesis showing pronounced diastolic abnormalities using the four chamber approach ( (b) arrows). The continuous wave (CW) recording shows increased early diastolic velocities approaching $2 \mathrm{~m} / \mathrm{s}$; mean value of pressure half time is $0.27 \mathrm{~s}$. Surgery showed obstructive postinfective alterations and a thrombus filling the left atrium up to the annulus. (Abbreviations as in previous figures.)

coronary cusp and one overriding the previous commissure between the coronary cusps. In this patient, however, an additional minor leak along the noncoronary cusp was overlooked.
One tear of the aortic left coronary cusp and two tears on the anterior (1) and posterior (1) mitral cusps were detected by Doppler, which failed to detect posterior tear on another bioprosthesis. There

Table 3 Comparison of pulsed Doppler and surgical findings for the size of the paravalvar leak

\begin{tabular}{|c|c|c|c|c|}
\hline \multirow[t]{2}{*}{ Type of prosthesis } & \multirow{2}{*}{$\begin{array}{l}\text { Ring diameter (mm) } \\
\text { at surgery }\end{array}$} & \multirow{2}{*}{$\begin{array}{l}\text { Width of annular } \\
\text { Doppler anomalies } \\
(\mathrm{mm})\end{array}$} & \multicolumn{2}{|c|}{ Leak/circumference } \\
\hline & & & Doppler (\%) & Surgery ${ }^{\star}$ \\
\hline $\begin{array}{l}\text { Mitral: } \\
\text { Björk } \\
\text { Björk } \\
\text { Starr } \\
\text { Starr } \\
\text { Bioprosthesis } \\
\text { Bioprosthesis } \\
\text { Bioprosthesis } \\
\text { Gabbay Meadox }\end{array}$ & $\begin{array}{l}31 \\
29 \\
30 \\
31 \\
31 \\
33 \\
31 \\
29\end{array}$ & $\begin{array}{r}28 \\
15 \\
30 \\
4 \\
20 \\
15 \\
28 \\
10\end{array}$ & $\begin{array}{r}28 \\
16 \\
31 \\
4 \\
20 \\
14 \\
28 \\
10\end{array}$ & $\begin{array}{l}1 / 3 \\
1 / 4 \\
1 / 3 \\
\text { Minimal } \\
20 \mathrm{~mm} \\
0 \cdot 10 \\
1 / 3 \\
8 \mathrm{~mm}\end{array}$ \\
\hline $\begin{array}{l}\text { Aortic: } \\
\text { Starr } \\
\text { Starr } \\
\text { Starr } \\
\text { Starr } \\
\text { St Jude }\end{array}$ & $\begin{array}{l}23 \\
23 \\
21 \\
23 \\
25\end{array}$ & $\begin{array}{l}22 \\
19 \\
25 \\
20 \\
10\end{array}$ & $\begin{array}{l}30 \\
26 \\
37 \\
27 \\
12\end{array}$ & $\begin{array}{l}1 / 3 \\
1 / 4 \\
2 \text { leaks }(8 \mathrm{~mm}, 12 \mathrm{~mm}) \\
1 / 3 \\
6 \mathrm{~mm}\end{array}$ \\
\hline
\end{tabular}

*Approximate size on the basis of visual inspection. 
Table 4 Surgical findings confirming the site of the prosthetic dysfunction

\begin{tabular}{lll}
\hline & $\begin{array}{l}\text { Aortic } \\
\text { prostheses }\end{array}$ & $\begin{array}{l}\text { Mitral } \\
\text { prostheses }\end{array}$ \\
\hline Regurgitation: & $4 / 5$ & \\
Site of paravalvar leak & $6 / 8$ \\
Site of valvar lesions on bioprostheses & $1 / 1$ & $2 / 3$ \\
Obstruction: & $2 / 2$ & $1 / 1$ \\
Site & \\
\hline
\end{tabular}

were no discrepancies in the results in the cases of obstruction.

\section{Discussion}

The difficulties encountered by non-invasive techniques in evaluating prosthetic dysfunction are often reported. Nevertheless, many limitations apply equally to the invasive procedures in the same circumstances, either because the association of two prostheses in a given patient does not allow haemodynamic studies or because repeat cardiac catheterisation is refused by patients. In our study, endocarditis was present in 14 cases, which in most cases caused regurgitation. When necessary, in view of the severity of the dysfunction, these patients underwent urgent surgery. The high incidence of dysfunctioning prostheses in our study in relation to the number of normal prostheses examined during the same period has, of course, no significance, since patients were referred to our laboratory from several hospitals for Doppler examination.

As already stated in a previous paper, ${ }^{26}$ because of the technological limitations inherent in the pulsed Doppler devices, particularly the Nyquist limit, we did not take into account the absolute velocities of flow traces but only their pattern and timing anomalies. For spectral anomalies, diagnosis relied on an all or none analysis, and not on the amplitude of the spectral broadening, which was susceptible to observer bias. Recent technological improvements tend to minimise these limitations. The colour coded Doppler apparatus recently introduced, however, does not solve all the problems raised by the quantification of regurgitation on prostheses mainly because of strong reverberation echoes. ${ }^{27}$ In brief, although limitations exist in the use of single gated Doppler, these should not detract from the value of the pulsed Doppler technique combined with cross sectional echocardiography.

\section{NORMAL PROSTHESES}

Postoperative invasive studies are not routinely performed in healthy subjects with prostheses. Thus only a few subjects were studied using invasive procedures, and because of this the overall specificity should be interpreted with caution. Nevertheless, this specificity is satisfactory for this small group. The few false positive diagnoses might be accounted for by the greater sensitivity of Doppler in detecting minimal backflow on a prosthesis. The Doppler features were similar to those previously reported. ${ }^{89}$ Fig. 4 shows that frequency aliasing may be present on normal prostheses. Flow velocities are frequently higher than those across a native valve, probably because of the presence of discrete transprosthetic pressure gradients. ${ }^{2829}$

\section{DYSFUNCTIONING PROSTHESES}

The predominant dysfunction encountered in our study was valvar regurgitation. The incidence of valvar obstruction is now lower because of improvements in the new generation of prostheses and the decreased incidence of thrombosis on bioprostheses. The diagnostic reliability of Doppler in our study, which was similar to that obtained in studies of stenoses on native valves, suggests that the pulsed Doppler technique is applicable to the study of prostheses. The same applies to continuous wave Doppler, as previously reported by others. ${ }^{79}$ Nevertheless, with the latter technique, the study of the half pressure time might be more sensitive than the increase in absolute velocities in detecting mitral obstruction since these patients often have low cardiac output. Low cardiac output is likely to be the cause of the false negative diagnosis of aortic obstruction since it produced a normal aortic velocity trace. The mapping of systolic disturbances at the aortic orifice might be more reliable but could not be performed in one patient because of unsatisfactory echocardiograms. This emphasises that one of the advantages of using pulsed Doppler is its ability to identify the site of the dysfunction. Fig. 5 shows that each cusp of a bioprosthesis may be the site of a different defect, each one requiring accurate evaluation.

Regurgitation is due to valvar tears in cases of bioprostheses and to paravalvar leaks in cases of mechanical and biological valves. In our study the mapping procedure using the long axis approach for aortic prostheses was as accurate as that used for native regurgitant valves. The diastolic disturbances were generally detected immediately below the aortic orifice, either anteriorly or posteriorly in the outflow tract depending on the site of the regurgitation. The calculation of the long axis regurgitant index caused overestimation in one patient with a mitral prosthesis and underestimation in one patient with a severely dilated ventricle. In cases of mitral regurgitation the findings differed considerably from those of native regurgitant valves. Regurgitations on native mitral valves generate central systolic disturbances at the point of the leaflet's coaptation. 
From this central point the jet is mapped point by point into the atrium. ${ }^{13}$ Surprisingly, this mapping pattern was rarely found on prostheses. Two patients with such findings underwent repeat surgery and both had a valvar tear on a bioprosthesis. Moreover, in both there was an unusual high pitched and musical tone, as already stressed in such cases by Sabbah et $\mathrm{al}^{30}$ These findings might be a feature of valvar defects.

On the other hand, the features encountered in patients with paravalvar mitral leaks were characterised by eccentricity of the jet. The centre of the prosthesis was free of disturbances. In addition, the jet could not be mapped in its entirety from the annular plane to its farthest atrial point, and the disturbances, sometimes seen only in a parallel long axis plane, were found at a variable distance in the atrium, which meant that some points had to be extrapolated between the disturbed area and the annulus for measurement of the length of the jet. Some conditions might alter the features of paravalvar leaks that we observed. Figure 2 shows that the prosthetic annulus is transsected by the echocardiographic plane at two opposite points where the leak may, or may not, be located. In the first instance only can the eccentric jet be mapped in its entirety. Moreover, some important leaks might entail a regurgitant flow in the central part of the atrium. None of these situations occurred in our preliminary study. The conditions entailing an eccentric jet also apply to aortic leaks, in which, however, the regurgitant jets are easily mapped. Reasons for that are unclear. Configuration and haemodynamics of the left atrium and ventricle are not similar, and the relation between chamber size and prosthesis is different. Furthermore, eccentricity of the jet increases with the diameter of the prosthesis.

With the short axis approach, the detection of the Doppler anomalies had a three fold interest. It first led to quantifying the regurgitation on the basis of a three dimensional index, as already proposed for native regurgitant valves. ${ }^{1314}$ Satisfactory grading was obtained because the three dimensional approach took into account the unusual features of some jets such as wide annular jets with limited upstream spread. Furthermore, provided that the mapping was performed at the actual site of the mitral and aortic orifices, this approach identified the site of the dysfunction with the same reliability as that for native valves. ${ }^{12}{ }^{13}$ Finally, Doppler mapping in the short axis view represented a unique ability to compare Doppler and invasive measurements. Indeed, in the case of paravalvar leaks, when the examiner measures the width of the Doppler anomalies at the prosthetic annulus he actually assesses the size of the leak. This size may be expressed as a

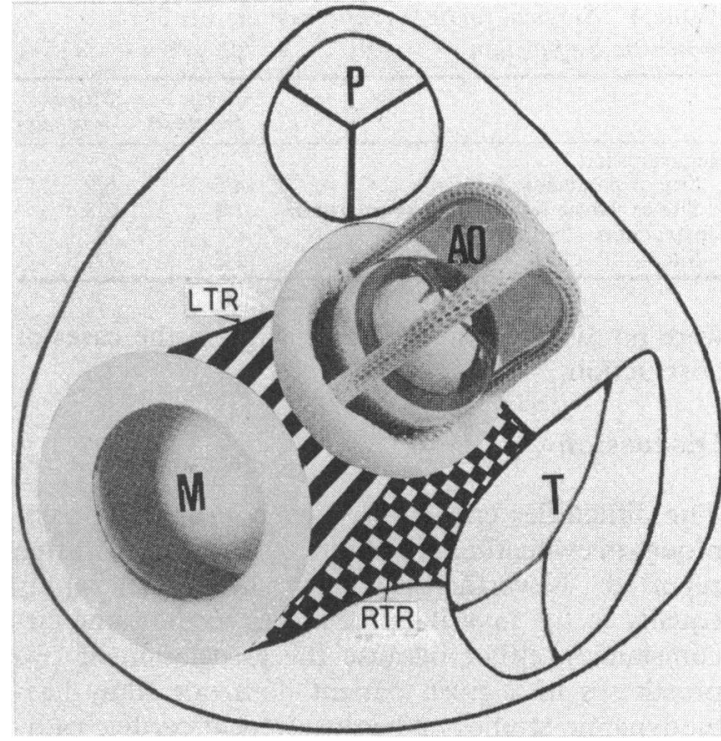

Fig. 8 Diagram of the anatomical relation of the heart valves showing the base of the heart, the atria having been removed. The anterior part of the prosthetic mitral annulus corresponds to the fibrous attachment of the previous anterior mitral leaflet, which involves for its anterior two thirds the left fibrous trigone, and for its posterior one third the right fibrous trigone. These relations need to be borne in mind when identifying the site of a dysfunction in a prosthesis because they explain, for instance, the preferential atrial direction of the jets due to mitral paravalvar leaks observed during the Doppler examination. ( $L$ and $R T R$, left and right trigone, other abbreviations as for previous figures.)

percentage of the whole circumference, since the prosthetic diameter is known, and correlated with the surgical findings, which are often based on the same calculation. The surgical assessment did not rely on accurate measurements but rather on visual inspection. Nevertheless, Table 3 shows that the Doppler estimation of the size of the leaks agreed with that found at surgery. This also applies to the 9 size of valvar defects. Differences in flow dynamics between the Doppler and surgical investigations might explain some discrepancies.

Furthermore, correlations with the surgical of findings suggest that generally the areas of disturbed $N$ flow were almost opposite the site of the leak. For $\underset{\omega}{N}$ instance, regurgitation due to paravalvar leaks along the previous attachment of the anterior mitral valve 0 spreads towards the upper atrial portion in the long $\mathbb{D}$ axis view and towards the interatrial wall in the api- ? cal view and conversely (Fig. 6). Some inaccuracies 0 regarding the leaks overriding the previous commissures will need further study. Some very small leaks may require repair because they cause severe dis- $\mathbb{D}$ 
turbance; sometimes they are difficult to detect at the time of operation. The use of the Doppler technique is crucial for their localisation. For this purpose, reference to standardised anatomical landmarks, such as the previous attachment of valves and commissures, is recommended to achieve better correlations. The Doppler examiner should always keep in mind the anatomical relations of the cardiac orifices, as shown in Fig. 8, when locating a defect.

\section{LIMITATIONS OF THE METHOD}

Low cardiac output, poor postoperative echocardiographic visualisation, and weak signal to noise ratio are well known factors that might produce false negative diagnoses or underestimations or both. The presence of a mitral prosthesis, mitral valve disease, or an irregular heart rhythm might make the measurement of aortic jets in the left ventricle difficult. Errors might be introduced into results when some measurements have to be extrapolated, but this was not a source of error in our study. In addition, poor lateral resolution is likely to be the cause of inaccurate measurements. Two closely associated defects causing the same disorder, such as a leak and a valvar tear, make diagnosis difficult. In one case of mitral obstruction due to prosthetic fibrosis we overlooked an additional cause, which was an atrial thrombus. The multigate Doppler technique might lead to more accurate information in such cases. Failure to map the eccentric jet in its entirety in the case of mitral leaks is, in fact, due to the inability of the present equipment to display the disturbed flows in a three dimensional frame and should be overcome in the future.

The work was partly supported by grants from CNAMTS and the ARNTIC Research Association.

\section{References}

1 Mintz GS, Carlson EB, Kotler MN. Comparison of noninvasive techniques in evaluation of the nontissue cardiac valve prosthesis. Am f Cardiol 1982; 49: 39-44.

2 Horowitz MS, Tecklenberg PL, Goodman DJ, Harrison DC, Popp RL. Echocardiographic evaluation of the stent mounted aortic bioprosthetic valve in the mitral position. In vitro and in vivo studies. Circulation 1976; 54: 91-6.

3 Bommer W, Yoon D, Grehl TM, Mason DT, Neumann A, Demaria AN. In vitro and in vivo evaluation of porcine bioprostheses by cross-sectional echocardiography [Abstract]. Am ₹ Cardiol 1978; 41: 405.

4 Mikell FI, Asinger RW, Rourke T. Two-dimensional echocardiographic demonstration of left atrial thrombi in patients with prosthetic mitral valves. Circulation 1979; 60: 1183-90.
5 Mehta A, Kessler KM, Tamer D, Pefkaros K, Kessler RM, Myerburg RJ. Two-dimensional echographic observations in major detachment of a prosthetic aortic valve. Am Heart $\mathcal{F}$ 1981; 101: 231-3.

6 Witchitz S, Veyrat C, Moisson P, Scheinman N, Rozenstajn L. Fibrinolytic treatment of thrombus on prosthetic heart valves. Br Heart $\mathcal{f}$ 1980; 44: 545-54.

7 Holen J, Nitter Hauge S. Evaluation of obstructive characteristics of mitral disc valve implants with ultrasound Doppler techniques. Acta Med Scand 1977; 201: 429-34.

8 Veyrat C, Cholot N, Abitbol G, Kalmanson D. Noninvasive diagnosis and assessment of aortic valve disease and evaluation of aortic prosthesis function using echo pulsed Doppler velocimetry. Br Heart $\mathcal{f} 1980$; 43: 393-413.

9 Nitter-Hauge S. Doppler echocardiography in the study of patients with mitral disc valve prostheses. $\mathrm{Br}$ Heart f 1984; 51: 61-9.

10 Kalmanson D, Veyrat C, Bouchareine F, Degroote A. Non-invasive recording of mitral valve flow velocity patterns using pulsed Doppler echocardiography. Application to diagnosis and evaluation of mitral valve disease. Br Heart $\mathcal{F}$ 1977; 39: 517-28.

11 Veyrat C, Villemot JP, Manin JP, Cabrol C, Kalmanson D. Anatomic and functional evaluation of pure and associated mitral stenoses using the EchoDoppler Scanner technique. Ultrasound Med Biol 1983; 9: 1-17.

12 Veyrat C, Lessana A, Abitbol G, Ameur A, Benaim R, Kalmanson $D$. New indexes for assessing aortic regurgitation with two-dimensional Doppler echocardiographic measurement of the regurgitant aortic valvular area. Circulation 1983; 68: 998-1005.

13 Veyrat C, Ameur A, Bas S, Lessana A, Abitbol G, Kalmanson D. Pulsed Doppler echocardiographic indices for assessing mitral regurgitation. Br Heart $\mathcal{F}$ 1984; 51: 130-8.

14 Veyrat C, Ameur A, Gourtchiglouian C, Lessana A, Abitbol G, Kalmanson D. Calculation of pulsed Doppler left ventricular outflow tract regurgitant index for grading the severity of aortic regurgitation. $\mathrm{Am}$ Heart $\mathcal{f} 1984$; 108: 507-15.

15 Kalmanson D, Veyrat C, Abitbol G, Farjon M. Doppler echocardiography and valvular regurgitation with special emphasis on mitral insufficiency; advantages of two dimensional echocardiography with realtime spectral analysis. In: Rijsterborgh $\mathrm{H}$, ed. Echocardiography. The Hague, Boston, London: Martinus Nijhoff, 1981: 279-90.

16 Baker DW, Rubenstein SA, Lorch GS. Pulsed Doppler echocardiography: principles and applications. Am $\mathcal{J}$ Med 1977; 63: 69-80.

17 MacPherson PC, Meldrum SJ, Tunstall-Pedoe DS. Angioscan: a spectrum analyser for use with ultrasonic Doppler velocimeters. f Med Eng Technol 1981; 5: 84-5.

18 Spencer MP, Hileman RE. Le Doppler à émission continue avec analyse spectrale de fréquences pour le diagnostic cardiologique en pathologie valvulaire acquise. $\mathcal{f}$ Imagerie Med 1983; 1: 17-29.

19 Veyrat C, Sebaoun G, Gramage JY, Dumora P, 
Kalmanson D. Comparaison des techniques Doppler pulsé et continu pour l'évaluation des sténoses valvulaires gauches. Arch Mal Coeur (in press).

20 Veyrat C, Kalmanson D, Farjon M, Guichard JP, Sainte-Beuve D, Abitbol G. Combined pulsed Doppler echocardiography for the investigation of valvular heart diseases: one- versus two dimensional approach. In: Rijsterborgh H, ed. Echocardiology. The Hague, Boston, London: Martinus Nijhoff, 1981: 291-8.

21 Nishimura K, Sakakibara T, Hibi N, et al. High speed ultrasonocardiotomography: echocardiographic manifestations of papillary muscles and chordae tendinae. $\mathcal{F}$ Cardiology 1977; 7: 1-13.

22 Hatle L, Brubakk A, Tromsdal A, Angelsen B. Noninvasive assessment of pressure drop in mitral stenosis by Doppler ultrasound. Br Heart $\mathcal{F} 1978$; 40: 131-40.

23 Hatle L, Angelsen BA, Tromsdal A. Non-invasive assessment of aortic stenosis by Doppler ultrasound. $\mathrm{Br}$ Heart f 1980; 43: 284-92.

24 Holen J, Aaslid R, Landmark K, Simonsen S. Determination of pressure gradient in mitral stenosis with a non invasive ultrasound Doppler technique. Acta Med Scand 1976; 199: 455-60.

25 Hatle L, Angelsen B, Tromsdal A. Noninvasive assess- ment of atrioventricular pressure half-time by Doppler ultrasound. Circulation 1979; 60: 1096-104.

26 Veyrat C, Abitbol G, Bas S, Manin JP, Kalmanson D. Quantitative assessment of valvular regurgitation using the pulsed Doppler technique. Approach to the regurgitant lesion. Ultrasound Med Biol 1984; 10: 201-13.

27 Omoto R, Yokote Y, Takamoto S, et al. The development of real-time two dimensional Doppler echocardiography and its clinical significance in acquired valvular diseases with special reference to the evaluation of valvular regurgitation. fpn Heart $\mathcal{f} 1984$; 25: 325-40.

28 Morris DC, Wickliffe CW, King SB, Douglas JS Jr, O Jones EL. Hemodynamic evaluation of the porcine xenograft aortic valve [Abstract]. Am $\mathcal{f}$ Cardiol 1976; 37: 157.

29 Horstkotte D, Haerten D, Seipel L, et al. Central hemodynamics at rest and during exercise after mitral valve replacement with different prostheses. Circulation 1983; 68 (suppl ii): 161-8.

30 Sabbah HN, Magilligan DJ Jr, Lakier JB, Stein PD. Hemodynamic determinants of the frequency and $\mathcal{S}$ amplitude of a musical murmur produced by a regurgitant mitral bioprosthetic valve. Am f Cardiol 1982; 50: 53-8. 